\title{
On the supposed existence of fluoric acid in animal matter
}

\section{G.O. Rees M.D. F.G.S.}

To cite this article: G.O. Rees M.D. F.G.S. (1839) On the supposed existence of fluoric acid in animal matter, Philosophical Magazine Series 3, 15:99, 558-560, DOI: 10.1080/14786443908649961

To link to this article: http://dx.doi.org/10.1080/14786443908649961

册 Published online: 01 Jun 2009.

Submit your article to this journal $₫$

Џ Article views: 2

Q View related articles $₫$ 


\section{Intelligence and Miscellaneous Articles.:-Dr. G. O. Rees}

which had struck the tree. It is to be hoped that further search will be made for other portions of this meteorite.

The total weight of all the fragments which $\mathrm{Mr}$. S. has brought home, is 973 grains. The specific gravity of one of the small fragments is 3.5 ; but different portions of the stone may vary slightly in this respect, as they may contain more or less of the metallic matter. The resemblance between this meteorite and those of Tennessee, (Silliman's Jour. xvii. 326.) of Georgia, (Ib. xviii. 389,) and of Weston, Conn., is very close, and one might almost imagine that they were all parts of the same original mass. The cohesion of the stone is not great, as it crumbles under a moderate blow. Two of the fragments retain portions of the crust or exterior coating. This is a fifteenth of an inch thick, and bears evidence of intense ignition and partial fusion. It is black, with a wrinkled or cellular surface, and is traversed with seams. The general colour of the interior is an ash-gray. The whole mass is studded with metallic particles, (varying from the size of small shot down to mere points,) and presents numerous rusty spots, and occasional small spheroidal concretions which do not appear to differ in materials from other parts of the stone. The little metallic masses (doubtless of nickeliferous iron) are attracted by the magnet, and are generally permeated by the earthy matter. 'They are mostly of an iron-white colour, but several are yellow and slightly iridescent. One of these minute masses being removed from the stone, it was by the hammer at once extended into a thin lamina, and was evidently malleable. An analysis may be expected hereafter.

Sept. 25, 1839.

E. C. Herrick.

Remark.-Having been familiar with meteorites and examined many of them, I hesitate not to say that I am perfectly assured of the genuine meteoric origin of the fragments described above, even without any reference to the testimony.-Sen. Ed. [Dr. B. SrLlrmaN] Silliman's Journal, vol. xxxvii. p. 385.

\section{ON THE SUPPOSED EXISTENCE OF FLUORIC ACID IN ANIMAI}

MATTER. BY G. O. REES, M.D., F.G.S.

In the year 1802 , Morichini published a paper, in which he declared fluoride of calcium to be an ingredient in human teeth: he was led to examine that substance, from having succeeded in detecting the fluoride in a specimen of fossil ivory. Mons. Gay-Lussac repeated these experiments: and in the 55th volume of the "Annales de Chimie," he states, that the fluoride exists in recent as well as in fossil ivory; and that he had also succeeded in detecting it in the tusks of the wild boar. Fourcroy and Vauquelin subsequently published a memoir in the 57 th volume of the "Anales de Chimie," in which they positively denied the existence of fluoride of calcium as an ingredient either in recent ivory or the enamel of teeth : they found it, however, in the fossil ivory of Argenteuil and Lourque, though it did not appear to exist in specimens from Siberia and Layo. 


\section{on the non-existence of Fluoric Acid in Animal Matter. 559}

Baron Berzelius has published a paper in the 61st volume of the "Annales de Chimie;" in which he states, fluoric acid may be detected in human teeth, bones, and urine; and may be demonstrated, in the latter case, by operating on the precipitate obtained from the excretion by means of lime-water. Since the publication of this paper by Baron Berzelius, the existence of fluoric acid, as a constituent of the animal substances above mentioned, has been acknowledged by chemists generally; and it is mentioned as such in the standard chemical works of the present day.

Having lately been engaged in the analysis of human bone, with more especial reference to those ingredients which have been stated to exist in small proportion, I was led to search particularly for fluoride of calcium. My experiments were made in the usual manner, by trying to obtain the corroding action of fluoric acid on a plate of glass, which was used as a loose cover to a platinum cru* cible, which contained the substance for examination, mixed with strong sulphuric acid. A gentle heat was applied to the bottom of the containing ressel. In this way, several specimens of human bone (both before and after calcination) were subjected to experiment; but in no instance could I obtain any action upon the glass.

The experiment which the Baron recommends, in order to obtain corrosion from bone-earth, is, to distil equal parts of strong sulphuric acid, and water upon it, until the measure of water is brought over. He states, that the distilied liquor, if evaporated in the glass receiver, will produce a corrosion.-I repeated this experiment using 100 grains of bone-ash, and an ounce of the acid mixture; but could obtain no action on the receiver, by evaporating the distilled liquor; nor was there any corrosion or opacity produced on any part of the apparatus.

During the evaporation of the last portions of the liquor, dense white fumes appeared; and there was some difficulty in vaporizing the whole of it. On neutralizing a portion with ammonia, and testing it with nitrate of silver, a yellow precipitate of phosphate of silver was thrown down. A further examination showed the presence of sulphuric acid, and traces of hydrochloric acid. I was much surprised to find phosphoric acid in this result of aqueous distillation, as the heat had not been urged during the process; for I had considered that acid as of too fixed a nature to volatilize with water at so low a temperature. It appeared to me now, that the presence of phosphoric acid, in this distilled liquor, might be a source of fallacy in the above experiment for establishing the presence of fluoric acid as a constituent of human bone; for it is a well-known fact, that phosphoric acid, if heated on glass of inferior quality till it volatilize, will act upon it with considerable energy*;

* It must be borne in mind, that the fluoric acid acts with facility on every kind of crown or flint glass, howerer good their quality may be. The supposition that bad glase was used in the experiment is the only means I have of explaining away that which I feel sure is an error on the part of several continental chemists. 
and all the animal substances in which fluorine has been said to exist, are particularly rich in phosphoric acid;-thus the ashes of ivory, of human bone, and the enamel of teeth, as also the precipitate obtained from urine by means of lime-water, are all of them composed, in very great part, of phosphate of lime. Mr. Richard Phillips has mentioned (in the Annals of Philosophy, vol. v.), that when the water contained in uranite is driven off from the powdered mineral, a portion of the phosphoric acid is volatilized with it; the lieat used being that of a common spirit-lamp. This is the only fact with which I am acquainted (with the exception of my own observation), to show that phosphoric acid will volatilize with water. The heat used in Mr. Phillips's experiment was, most probably, considerably higher than any which I applied. There seems no doubt that phosphoric acid is much more volatile than it has heretofore been supposed.

Having failed in detecting fluoric acid in human bones, I determined on testing for its presence in the enamel of teeth, in recent ivory, and in the precipitate obtained from urine by the addition of lime-watcr. Two different specimens of ivory (tusks of the elephant) gave no evidence of the presence of fluoric acid, when carefully tested, either before or after calcination; and I was equally unsuccessful with the enamel of human teeth and the precipitate from the urine *.

In these experiments, when I had failed in acting on the glass, I always found that the addition of 0.3 grains of fluoride of calcium to the experiment produced a strong and indelible mark on the surface of the glass test-plate. I mention 0.3 grains, because it will always be found sufficient to produce a most unequirocal corrosion; though I obtained satisfactory results by the addition of a much less quantity. 1 have had only one opportunity of examining fossil ivory; and in that instance I could not ascertain its locality : on submitting it, however, to the tests used for recent ivory, bone, \&c., I obtained immediate action on the glass.

In conclusion, I must express my firm conviction, that fluoride of calcium, as an ingredient in fossil ivory, must be regarded as an extraneous matter, introduced by the partial mineralization of the animal substance; - that no such constituent exists in recent ivory, the enamel of teeth, human bone, or urine;-in fact, that fluoride of calcium should be expunged from the list of the constituents of animal substances. -Guy's Hospital Reports, Aug. 1839.

* I was much pleased to observe, that Mr. Pepys, in an analysis of enamel published in Mr. Fox's work on the Teeth, does not mention fluoride of calcium as an ingredient of that substance. This analysis was made by Mr. Pepys in 1833, several years after the fluoride had been declared a constituent of the enamel. 